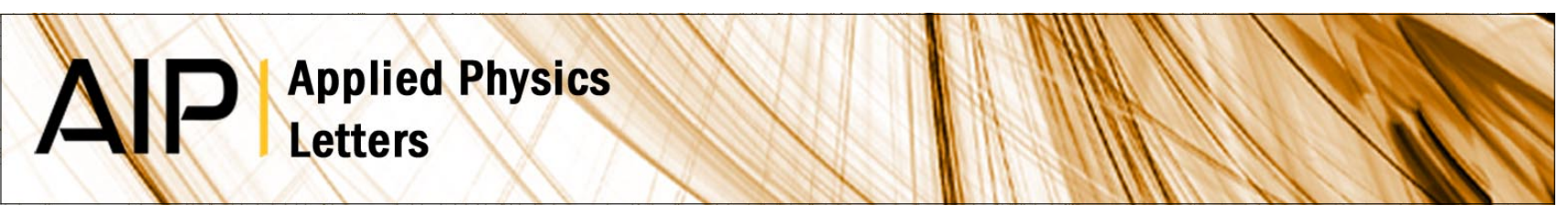

\title{
Optical determination of the direct bandgap energy of lead iodide crystals
}

A. Ferreira da Silva, N. Veissid, C. Y. An, I. Pepe, N. Barros de Oliveira et al.

Citation: Appl. Phys. Lett. 69, 1930 (1996); doi: 10.1063/1.117625

View online: http://dx.doi.org/10.1063/1.117625

View Table of Contents: http://apl.aip.org/resource/1/APPLAB/v69/i13

Published by the American Institute of Physics.

Additional information on Appl. Phys. Lett.

Journal Homepage: http://apl.aip.org/

Journal Information: http://apl.aip.org/about/about_the_journal

Top downloads: http://apl.aip.org/features/most_downloaded

Information for Authors: http://apl.aip.org/authors

\section{ADVERTISEMENT}

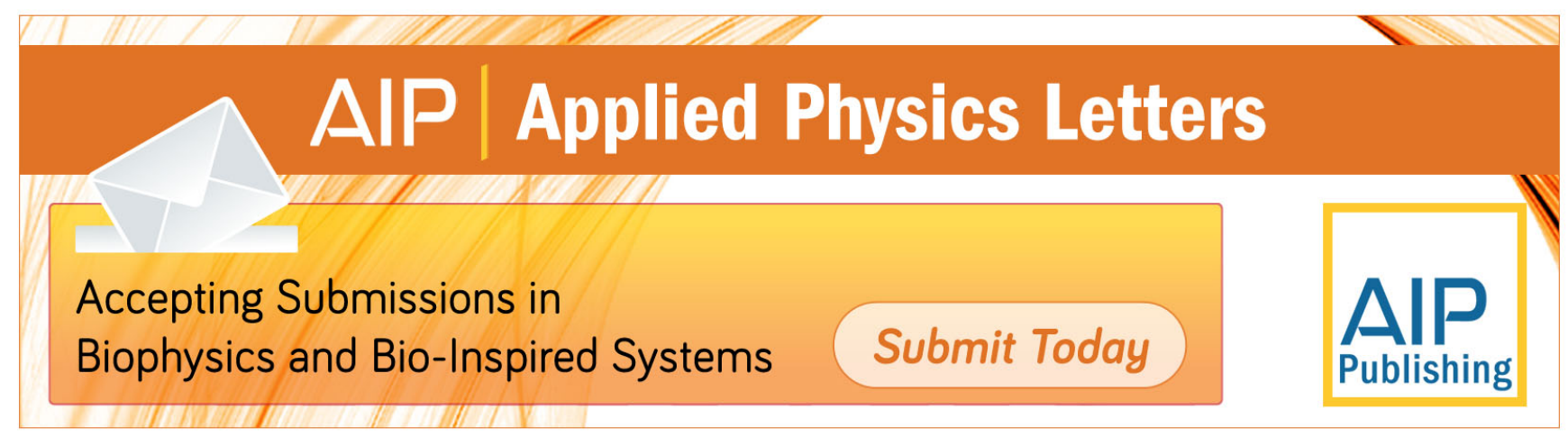




\title{
Optical determination of the direct bandgap energy of lead iodide crystals
}

\author{
A. Ferreira da Silva, ${ }^{\text {a) }}$ N. Veissid, and C. Y. An \\ Laboratório Associado de Sensores e Materiais, LAS, Instituto Nacional de Pesquisas Espaciais, INPE, \\ C.P. 515, 12201-970 São José dos Campos, SP, Brazil \\ I. Pepe, N. Barros de Oliveira, and A. V. Batista da Silva \\ Laboratório de Otica, Instituto de Física, Universidade Federal da Bahia, 40210-340 Salvadore, Ba, Brazil
}

(Received 12 June 1996; accepted for publication 17 July 1996)

\begin{abstract}
The optical bandgap energy of lead iodide $\mathrm{PbI}_{2}$, grown by Bridgman's method, is obtained by photoacoustic spectroscopy. Due to its potential applications, as a room temperature, semiconductor material detector, which may be used as a photocell, or as a $\mathrm{x}$ - and $\gamma$-ray radiation detector, the physical properties of $\mathrm{PbI}_{2}$ have attracted much attention. We computed, by different methods the bandgap energy. We found the energy in a range $2.301 \pm 0.038 \leqslant\left\langle E_{g}\right\rangle \leqslant 2.359 \pm 0.037 \mathrm{eV}$. (C) 1996 American Institute of Physics. [S0003-6951(96)04439-7]
\end{abstract}

Lead iodine, $\mathrm{PbI}_{2}$, is an intrinsic wide bandgap semiconductor $\left(E_{g}>2 \mathrm{eV}\right)$ composed by elements with large atomic number $\left(Z_{\mathrm{Pb}}=82\right.$ and $\left.Z_{\mathrm{I}}=53\right)$. This material has been the subject of many investigations due to specific technological features, for instance, its large applicability, at room temperature, as photocell, and $\mathrm{x}$ - and $\gamma$-ray detector. ${ }^{1-6} \mathrm{PbI}_{2}$ is more attractive than other similar materials, such as $\mathrm{HgI}_{2}$, because of its lower vapor pressure and lack of a destructive phase transition, which shows up at temperature around $130{ }^{\circ} \mathrm{C}$ for $\mathrm{Hg}_{2}$. $1,2,5,7-9$

This work reports on the optical absorption of $\mathrm{PbTz}$ in the region of the fundamental band edge. From the analysis of the data the bandgap energy, $E_{g}$, is obtained. This parameter is of great importance in electronic and optoelectronic design. A photoacoustic spectroscopy (PAS) technique has been used for the measurements PAS has attracted much attention as useful nondestructive method for studying the optical properties of semiconductors. ${ }^{8,10-15}$ The spectra are obtained directly from the heat generated in a sample, due to nonradiative absorption processes.

In the present investigation, the starting material for crystal growth was prepared using Merck resublimed iodine and lead powder (100 mesh), both $99.9 \%$ purity.

The elements were reacted in a vacuum sealed quartz ampoule ( $2 \mathrm{~mm}$ thickness, $18 \mathrm{~mm}$ inner diameter, and $25 \mathrm{~cm}$ length), with the weight ratio obeying the stoichiometric composition of $\mathrm{PbI}_{2}$, resulting in a total mass of $\sim 50 \mathrm{~g}$.

The sealed ampoule was subjected to a temperature of $430{ }^{\circ} \mathrm{C}$ during $48 \mathrm{~h}$ to synthesize a homogeneous compound. Since the element iodine has a large vapor pressure, the furnace was heated very slowly $\left(50^{\circ} \mathrm{C} /\right.$ day $)$ in order to allow a considerable time for reaction. If $\mathrm{Pb}$ and $\mathrm{I}_{2}$ are reacted under a higher heating rate, the released exothermic energy might heat the uncombined $\mathrm{I}_{2}$, leading to the possibility of an explosion at the ampoule due to excessive pressure.

For single crystal preparation a tipped-end quartz ampoule (10-8 $\mathrm{mm}$ diam, $\sim 200 \mathrm{~mm}$ length), loaded with reacted $\mathrm{PbI}_{2}(\sim 10 \mathrm{~g})$ and sealed under vacuum of $\sim 10^{-5}$

\footnotetext{
${ }^{a)}$ Temporary address: Linköping University, Department of Physics and Measurement Technology, S-58183 Linköping, Sweden. Electronic mail: ferreira@las.inpe.br
}

Torr, was placed in a furnace for growth by vertical Bridgman's method.

After heating, the upper furnace (starting ampoule position) is maintained at about $40{ }^{\circ} \mathrm{C}$ above the melting point $\left(408{ }^{\circ} \mathrm{C}\right.$ ) of the compound, and then, the crystal growth is performed by dropping the ampoule at a rate of about 2 $\mathrm{mm} / \mathrm{h}$ through a freezing gradient of $10{ }^{\circ} \mathrm{C} / \mathrm{cm}$.

The growth resulted in a $\mathrm{PbI}_{2}$ single crystal $(\sim 30$ $\mathrm{mm}$ length, $8 \mathrm{~mm}$ diam) with the $c$-axis oriented perpendicular to the growth axis.

The experimental apparatus for PAS measurements is shown in Fig. 1. A $230 \mathrm{~W}$ tungsten lamp and a $100 \mathrm{~W}$ mercury lamp are used as light sources. The latter is used as a calibration source. The reflective beam passes through a collimator, a plane reflection gratings, a set of lens, and a mechanical chopper (with a modulation frequency varying between 15 to $90 \mathrm{~Hz}$ ), producing a monochromating light focused onto a sample holder assembly which is inside the photoacoustic cell.

The PA signal produced is processed by using a preamplifier and a lock-in amplifier. The resultant PA spectra are recorded in a computer, which simultaneously displays the wavelength/energy dependent absorption intensity as shown in Fig. 2

To obtain the optical bandgap energies, we have applied the following methods.

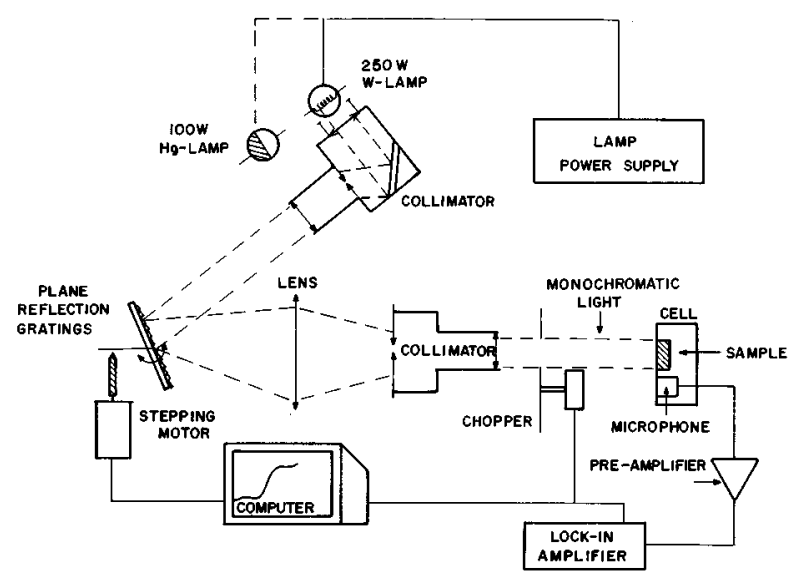

FIG. 1. The schematic experiment setup of the photoacoustic spectroscopy. 


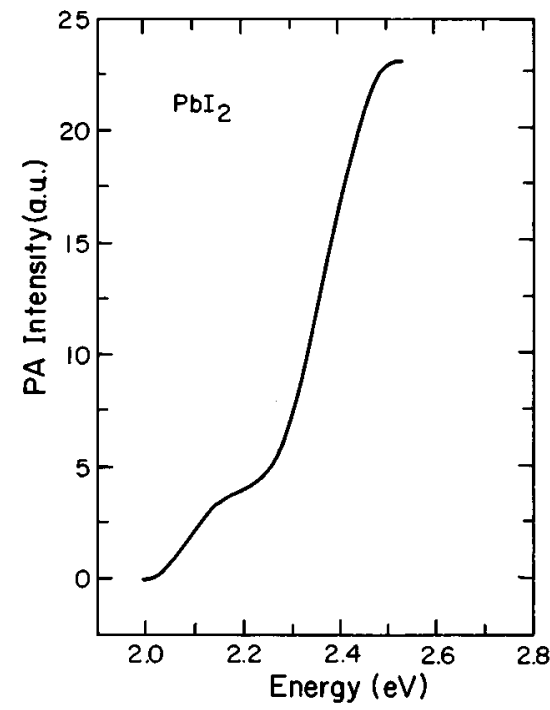

FIG. 2. Room temperature PA intensity spectrum of $\mathrm{PbI}_{2}$ as a function of photon energy. First measurement.

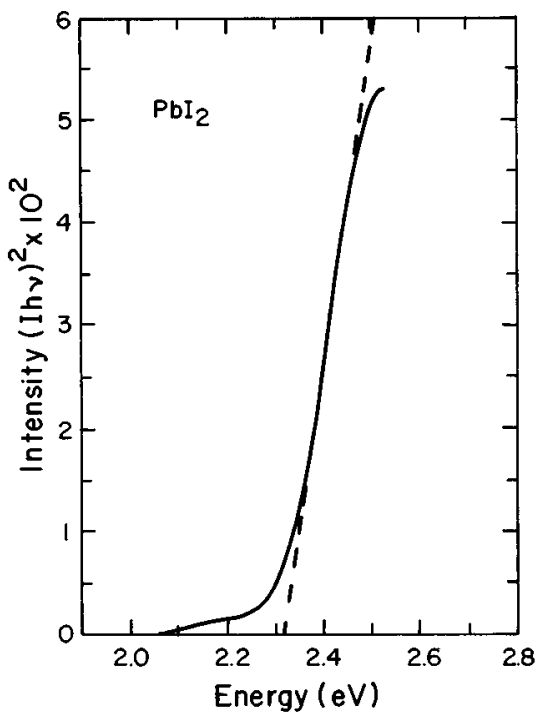

FIG. 3. Intensity $(I h v)^{2}$ of $\mathrm{PbI}_{2}$ as a function of photon energy near the fundamental absorption edge at room temperature. The dashed line crosses the energy axis at $2.317 \pm 0.033 \mathrm{eV}$, corresponding to the first measurement of Table I.

TABLE I. Values of the bandgap energy for the direct transition $\left(E_{g}^{d t}\right)$ and derivative $\left(E_{g}^{d v}\right)$ methods, respectively, $\left\langle E_{g}\right\rangle$ stands for the computed average. NM is the number of measurements.

\begin{tabular}{ccc}
\hline \hline $\mathrm{NM}$ & $E_{g}^{d t}(\mathrm{eV})$ & $E_{g}^{d v}(\mathrm{eV})$ \\
\hline 1 & $2.317 \pm 0.033$ & $2.377 \pm 0.031$ \\
2 & $2.312 \pm 0.044$ & $2.358 \pm 0.042$ \\
3 & $2.267 \pm 0.041$ & $2.329 \pm 0.041$ \\
$\left\langle E_{g}\right\rangle$ & $2.301 \pm 0.038$ & $2.359 \pm 0.037$ \\
\hline \hline
\end{tabular}

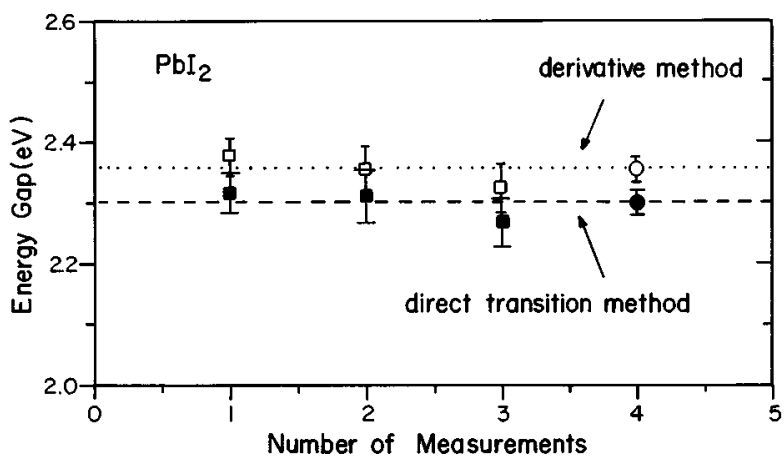

FIG. 4. Bandgap energy dependence on the repeated measurements of $\mathrm{PbI}_{2}$, for derivative and direct transition methods, respectively. The open and full circles correspond to the averaged values of them.

(1) The first makes use of the relation for allowed direct transitions ${ }^{8,16,17}$

$$
\operatorname{Ih} v=A\left(h v-E_{g}{ }^{d t}\right)^{1 / 2},
$$

where $I$ is the absorption intensity, $A$ a coefficient, and $h v$ is the photon energy. The value of $E_{g}^{d h}$ has been obtained by the extrapolation of the best-fit line between $(I h v)^{2}$ and $h v$ up to the point where it crosses the ordinate axis, as shown in Fig. 3.

(1) In the second, we have evaluated the derivative of the intensity signal near the fundamental absorption edge, leading to $E_{g}^{d v}$.

To improve accuracy, we have repeated the measurements three times and calculated the respective errors each time. The final result was obtained by averaging over these three independent results. In Table I, we show the bandgap energies for all situations described above.

Figure 4 shows the bandgap energy as a function of Number of Measurements, NM. The open and full squares with error bars correspond to the derivative and direct transition method, respectively. The open and full circles correspond to the average of the respective methods.

In summary, we have investigated through the PAS technique, and different methods, the optical bandgap energy, of $\mathrm{PbI}_{2}$. This semiconductor has shown to have a pronounced $E_{g}$, above $2 \mathrm{eV}$, proving to be an excellent material for detecting devices at room temperature.

${ }^{1}$ J. C. Lund, K. S. Shah, M. R. Squillante, L. P. Moy, F. Sinclair, and G. Entine, Nucl. Instrum. Methods Phys. Res. A 283, 299 (1989).

${ }^{2}$ J. C. Lund, K. S. Shah, F. Olschner, J. Zhang, L. Moy, S. Medrick, and M. R. Squillante, Nucl. Instrum. Methods Phys. Res. A 322, 464 (1992).

${ }^{3}$ J. Eckstein, B. Erler, C. Eiche, and K. W. Beng, J. Cryst. Growth 131, 453 (1993)

${ }^{4}$ K. S. Shah, J. C. Lund, F. Olschner, P. Bennett, J. Zhang, L. P. Moy, and M. R. Squillante, Nucl. Instrum. Methods Phys. Res. A 353, 85 (1994).

${ }^{5}$ M. A. George, M. Azoulay, H. N. Jayatirth, Y. Biao, A. Burger, W. E. Collins, and E. Silberman, J. Cryst. Growth 137, 299 (1994).

${ }^{6}$ T. Shoji, K. Ohba, T. Suchiro, and Y. Hiratate, IEEE Trans. Nucl. Sci. 42, 659 (1995).

${ }^{7}$ A. Burger, S. H. Morgan, E. Silberman, D. Nason, and A. Y. Cheng, Nucl. Instrum. Methods Phys. Res. A 322, 427 (1992).

${ }^{8}$ A. Ferreira da Silva, N. Veissid, C. Y. An, J. Caetano de Souza, A. V. Batista da Silva, P. Cesar Farias, and M. T. F. da Cruz, J. Appl. Phys. 78, 5822 (1995), and references therein

${ }^{9}$ M. Gonzalez and A. Ibarra, Phys. Rev. B 51, 13786 (1995). 
${ }^{10}$ T. Ikari, A. Fukuyama, K. Maeda, K. Futagami, S. Shigetomi, and Y. Akashi, Phys. Rev. B 46, 10173 (1992).

${ }^{11}$ J. Caetano de Souza, A. Ferreira da Silva, and H. Vargas, J. Phys. (Paris) IV Colloq 4, C7-129 (1994).

${ }^{12}$ O. Zelaya-Angel, J. J. Alvardo-Gil, R. Lozada-Morales, H. Vargas, and A. Ferreira da Silva, Appl. Phys. Lett. 64, 291 (1994).

${ }^{13}$ S. A. Thomás, O. Vigil, J. J. Alvarado-Gil, R. Lozada-Morales, O. ZelayaAngel, H. Vargas, and A. Ferreira da Silva, J. Appl. Phys. 78, 2204 (1995).
${ }^{14}$ A. K. Ghosh, K. K. Som, S. Chatterjee, and B. K. Chaudhuri, Phys. Rev. B 51, 4842 (1995).

${ }^{15}$ T. Ikari, S. Shigetomi, and Y. Koga, Photoacoustic and Thermal Wave Phenomena in Semiconductors, edited by A. Mandelis (Elsevier, New York, 1987), p. 397.

${ }^{16}$ J. Tauc, in Amorphous and Liquid Semiconductors, edited by J. Tauc (Plenum, New York, 1974), Chap. 4.

${ }^{17}$ J. I. Pankove, Optical Processes in Semiconductors (Dover, New York, 1975). 